\title{
Cohabitando hombres y espíritus, el territorio embera-chamí de Cañabravita, departamento del Putumayo (sur de Colombia)
}

Cohabitating men and spirits, the territory embera-chamí of the reservation Cañabravita, department of Putumayo (south of Colombia)

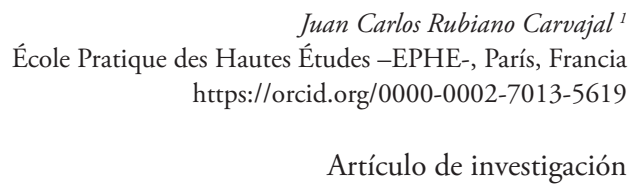

Fecha de recepción: 10 de octubre de 2018 Fecha de aceptación: 4 de diciembre de 2018

\section{Para citar este artículo}

Rubiano Carvajal, J. C. (2019). Cohabitando hombres y espíritus, el territorio emberachamí de Cañabravita, departamento del Putumayo (sur de Colombia). Campos en Ciencias Sociales, 7(1), 103-125. DOI: https://doi.org/10.15332/25006681.4758

1 Doctor en Antropología. Correo electrónico: juancarlos.rubiano@yahoo.fr 


\title{
RESUMEN
}

La manera como los embera-chamí conciben, establecen el acceso, el control y el uso del territorio se enmarca en el modo como ellos perciben e interactúan con los otros componentes del medio en el cual habitan; lo cual se hace a partir de concebir el entorno y sus componentes como seres; y el relacionamiento con ellos como homólogo al tipo de relaciones que existen entre los seres humanos. Esta percepción implica que el manejo del territorio se encuadra en redes de poder que legitiman la posición social del jaibaná; generando simultáneamente mecanismos para dominar, salvaguardar y socializar el territorio.

Palabras clave: control, embera, territorio.

\begin{abstract}
The way the Embera-Chamí envisage, establish access, control and use of the territory is framed by the way they perceive and interact with the other components of the environment in which they inhabit. This is done from conceiving the environment and its components as beings; and the relationship with them as a counterpart to the kind of relationships that exists between human beings. This perception implies that the management of the territory is framed in networks of power that legitimize the social position of the jaibaná; simultaneously generating mechanisms to dominate, safeguard and socialize the territory.
\end{abstract}

Keywords: control, embera, territory. 


\section{INTRODUCCIÓN}

El cabildo de Cańabravita se localiza en el municipio de Orito, en la inspección de Tesalia, toma su nombre de una quebrada que atraviesa la zona, es el más pequeńo de todos los asentamientos embera-chamí del departamento del Putumayo, constaba de 41 hectáreas a inicios del año 2000, pero para el año 2011 poseía 129.3 hectáreas; dicha ampliación se debe fundamentalmente a terrenos adquiridos en el marco de acuerdos en procesos de consulta previa con empresas petroleras. El terreno original fue adquirido por el jaibaná Ángel Dovigama, hace más de treinta años, cuando él llegó al Putumayo proveniente del departamento de Risaralda, de donde migró a causa de la lejanía de la zona donde habitaba de los centros poblados y la disminución de las propiedades productivas del medio, a causa del uso continuo. Este terreno tiene unas pocas áreas de bosque, que son fundamentales para la existencia de plantas medicinales y seres sobrenaturales, en tanto que las áreas abiertas son ocupadas por los embera (los hombres).

La zona donde se localiza el cabildo de Cańabravita se caracteriza por ser un terreno ondulado con la presencia de sistemas de colinas bajas disectadas, con cimas redondeadas y lomos angostos; laderas rectas, cóncavas y cortas; pendientes que van de moderadas a fuertemente inclinadas ( 25 y $50 \%$ ); las coberturas que se desarrollan sobre estas colinas son predominantemente antrópicas. Se presenta disección de drenajes de fuerte pendiente con valles estrechos. Se evidencian procesos de erosión y remoción en masa representados por flujos de tierra y deslizamientos superficiales; la intervención del medio ambiente natural ha dado lugar al establecimiento de unidades de paisaje con diferentes grados de transformación, con dominancia de los pastos limpios, en estrecha relación con la ganadería de doble propósito, y algunas áreas con cultivos de autoconsumo, en las cuales predomina la siembra de plátano primitivo (Musa acuminata). También se encuentran bajos inundables, que son zonas de origen fluvial, de pendiente ligeramente plana (0 a $3 \%)$ de forma cóncava ubicadas en la base de las colinas y hacia las cuales drena la escorrentía de las laderas que inunda el área. El agua satura los materiales arcillosos y drena muy lentamente hacia los cauces principales a través de drenajes poco profundos de baja pendiente; la zona permanece la mayor parte del tiempo con niveles importantes de agua. En áreas anexas a las quebradas y caños, se encuentran planicies de inundación, que son 
zonas de baja pendiente (0 a $3 \%$ ), localizadas al mismo nivel del cauce, conformadas por materiales generalmente de carácter arcilloso, periódicamente inundables en épocas de crecientes de las corriente; en esta misma área se pueden localizar terrazas aluviales altas, que son formas del terreno de baja pendiente (0 a $3 \%$ ), localizadas a niveles superiores al cauce $(3 \mathrm{a} 10 \mathrm{~m}$ ) y separadas del mismo por las zonas de inundación y las terrazas bajas, aunque en ocasiones están ubicadas desde el borde del talud de la corriente y separadas del cauce activo por taludes de pendiente fuerte. En cuanto a los suelos, en las zonas de colinas se encuentra la asociación LUB, son suelos moderadamente profundos, bien drenados, de texturas finas, fuertemente ácidos y de baja fertilidad; en las laderas y planos de terrazas predomina la asociación VUB, estos son suelos profundos, bien drenados, de texturas moderadamente finas, extremadamente ácidos, de muy alta saturación de aluminio y fertilidad baja y muy baja. En la planicie de inundación y en los bajos inundables se encuentra la asociación VUA, en donde los suelos son muy superficiales, las texturas son finas y muy finas, los suelos van de muy pobremente a bien drenados, en cuanto a la presencia de ácidos de muy fuertemente a extremadamente ácidos, son de media a muy alta saturación de aluminio y de fertilidad moderada a alta.

\section{La interconexión del territorio: un punto de partida}

Para los embera-chamí, el mundo está dividido en tres niveles, que simultáneamente pueden subdividirse en varios: en el nivel superior habitan seres como el sol o la luna, en el nivel del medio habitan los embera (hombres) pero también los kapunia (blancos) o los jä̈, en el nivel inferior se encuentran las dueńas o madres de los animales o plantas (las wadra).

Estos tres niveles están interconectados, no solo geográficamente, sino también desde el punto de vista de las relaciones políticas, económicas, chamánicas y de parentesco; es decir, los tres hacen parte de un todo espacial y sus habitantes de un todo social. El presente escrito se centrará sobre el nivel del medio por ser el de mayor actividad para los embera-chamí.

Antes de continuar, se debe indicar que para los embera-chamí la dicotomía hombreespíritu es inexistente; para ellos, los dos hacen parte de una misma realidad, de un 
único conjunto social, y ello se expresa en el territorio, pero, ¿cómo es la relación entre estas sociedades? La relación entre los diferentes ocupantes de un territorio está mediada por la ocupación del mismo, por ende, está enmarcada en interacciones de orden político, económico y de parentesco.

El presente escrito correlacionará el territorio, sus ocupantes y las formas de control que practican (seguridad), con el objeto de asegurar el control y uso del territorio. Como lo manifestó Foucault (2008), existe una estrecha interrelación entre territorio, seguridad y población; para comprender dicha relación, se parte de percibir el espacio como un medio y el medio como un soporte donde circulan los elementos de una acción.

Como se verá en las páginas siguientes, las relaciones de parentesco toman un rol preponderante en los mecanismos de apropiación y derecho de uso del territorio, en la protección del mismo, en la formación y mantenimiento de relaciones de orden social. En la conformación y mantenimiento de dichas interacciones, el jaibaná (chamán) tiene un rol preponderante, siendo ellas, simultáneamente, las que le dan la posibilidad de ejercer su influencia en la manera de usar el territorio.

El presente artículo consta de tres partes: en la primera se hace la presentación del cabildo de Cañabravita y de los grupos que lo habitan, en la segunda se presentan las tácticas utilizadas para controlar el territorio y sus habitantes, y en la tercera parte se analizan las estrategias empleadas por los embera-chamí para poder hacer uso del territorio.

\section{El territorio del cabildo de Cañabravita y sus habitantes}

En el año 2011 el cabildo estaba habitado por 79 individuos, 41 hombres y 38 mujeres, de los cuales 41 eran mayores de 18 años y 10 menores de 5 años; organizados en 20 familias. Las viviendas, que son en palafitos ${ }^{2}$, se encuentran dispersas y por

2 Casas construidas sobre pilares, en el caso embera-chamí se dice que ello se hace para estar a salvo del aribada quien no puede trepar por los postes. 
lo general a proximidad de la vía que conduce del centro poblado de Tesalia al de Simón Bolívar; en torno a las viviendas se localizan áreas de cultivos que son propiedad de los habitantes de la casa, existen unas pocas tierras y cultivos, sobresalen el plátano primitivo, el maíz, la yuca y la piña. Es de señalarse que los hombres son los responsables del desmonte, quema y siembra de los cultivos, las mujeres del deshierbe y de la cosecha de los productos.

Adicionalmente, el territorio es ocupado por no humanos (seres inmateriales o espirituales como la comunidad misma se refiere a ellos), tales como los jä̈, el aribadas o la wadra; para el caso del cabildo de Cañabravita estos seres y la ubicación espacial de su residencia son (Figura 1):

- Los jaïs (que residen en una jaïde o casa jai): ellos son seres inmateriales que están emparentados con los embera y que por lo general entran en contacto con ellos por intermedio del jaibaná. Estos seres poseen diferentes corporalidades, una por cada ser o cosa que existe en el mundo material, cada uno de ellos posee una personalidad propia (por ejemplo le gusta la pelea o es muy sociable). Sus sitios de residencia son análogos a las cabeceras municipales colombianas (tienen cárcel, alcaldía, iglesia, calles y casa). Su ubicación dentro del territorio se representa con un círculo amarillo en la figura.

- La wadra o dueña de los animales, reside en los sitios identificados con un rombo verde. Estos seres que controlan la vida de las plantas y animales, están en contacto con el jaibaná y mediante las negociaciones que estos últimos establecen con la wadra, los embera pueden obtener accesos a plantas y animales.

- El documa (marrano de agua) es un ser inmanente al territorio, reside por lo general en los charcos de los cursos de agua, pero también en las desembocadura de ellos. Son seres agresivos por naturaleza, protegiendo de manera violenta su territorio, es decir que atacan a todo aquel que se aproxima a él; salvo cuando están bajo el control de un jaibaná. Su ubicación en el territorio se representa con un triangulo gris. 
- El aribada es un muerto resucitado, para transforma el cuerpo de un muerto en este ser se requiere de una acción ritual de parte de un jaibaná, al ser la creación de un jaibaná, él permanece bajo su autoridad. El sitio de residencia del aribada se encuentra identificado con un hexágono de color rosado.

- El sitio donde habita el doniur (negro de agua) se identifica con un cuadrado de color azul. Como el documa, es un ser inmanente al territorio y reside por lo general en los charcos de los cursos de agua y en las desembocaduras de ellos. Son seres agresivos por naturaleza, protegiendo de manera violenta su territorio.

Antes de avanzar es importante aclarar que seres como el aribada, el doniur o el documa, tienen una corporeidad material, como la de los hombres. Adicionalmente, se debe mencionar que la presencia del doniur, del documa o de la wadra en un territorio es ajena a la actividad humana, ellos residían en el territorio antes de la llegada de los embera ${ }^{3}$; caso contrario al aribada que es un ser humano transformado.

Figura 1. Corporeidad de los habitantes del nivel del medio

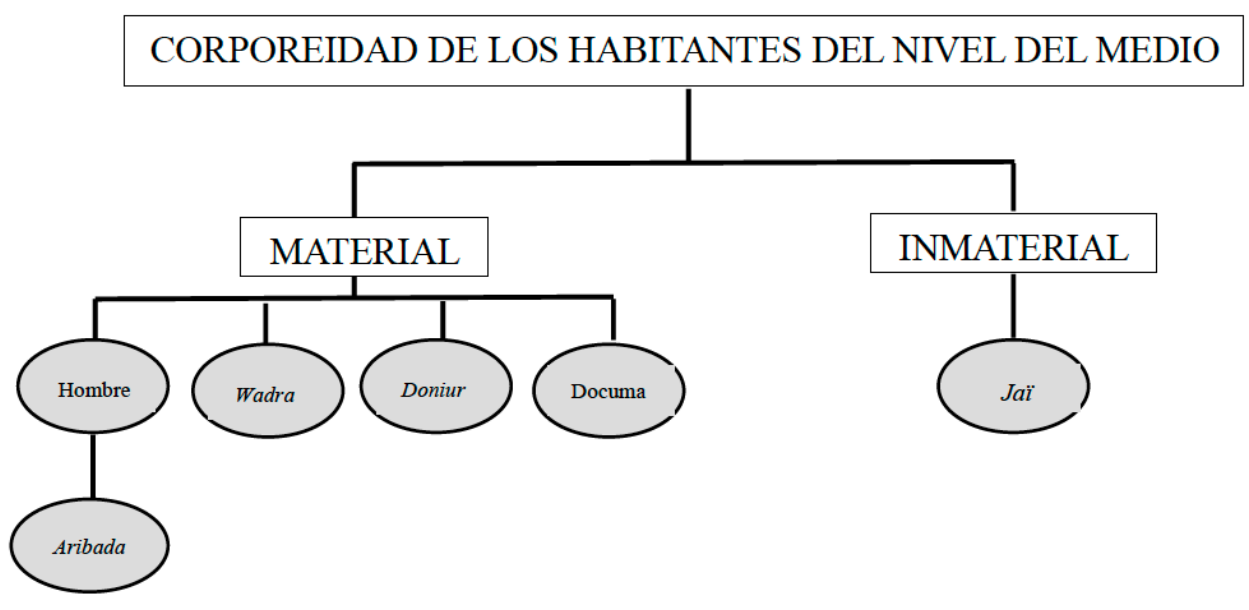

Fuente: elaboración propia.

3 En adelante se utilizará la palabra embera para hacer referencia a los embera-chamí. 
El caso de los jaïs es muy diferente, ellos al igual que los embera, son una comunidad migrante, tienen un modo de residencia seminómada, se desplazan en el viento y principalmente en el agua. Su permanencia en un territorio está ligada a la acción de un jaibaná que los encierra en una jä̈de (casa jai), pero este "encierro" no es una reclusión, lo que se les reconoce es una territorialidad. La razón se encuentra en el sistema de alianza que liga a los embera con los jaïs, como lo señaló Rubiano (2010), las relaciones entre estos dos grupos están centradas en un complejo sistema de parentesco en donde los jaïs (pero no exclusivamente ellos, porque también lo pueden hacer las wadras) otorgan mujeres (esposas) a los jaibanás, lo que hace automáticamente que los hijos humanos y no humanos de estos sean hermanos. En otras palabras, los embera y los jaïs que cohabitan en un territorio hacen parte de una misma o de varias familias consanguíneas.

Como se mencionó anteriormente el territorio es compartido por los emberas y los seres no humanos, todos comparten un espacio geográfico, pero se ubican en zonas específicas al interior del mismo, en el caso del cabildo de Cańabravita, ello ocurre como se observa en la Figura 2. 
Figura 2. El territorio del cabildo de Cañabravita y sus habitantes en el año 2002

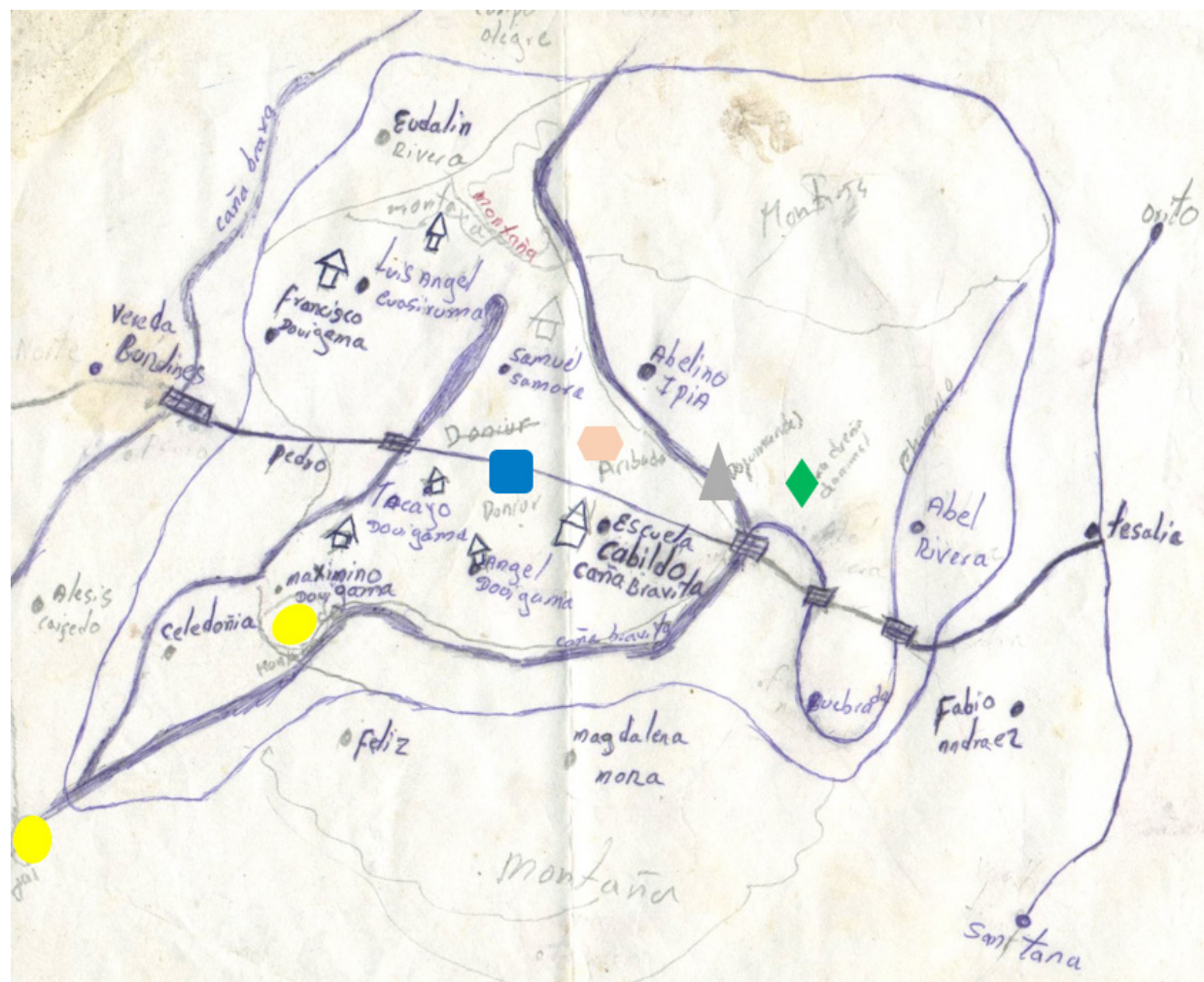

Fuente: Rubiano $(2010)^{4}$.

La Figura 2 presenta el cabildo de Cańabravita con las ampliaciones que tuvo el territorio entre el 2002 y el 2011, tres nuevos sitios ocupados por seres inmateriales se incorporan a las áreas identificadas en el año 2002 (los cuales se asocian a jä̈de).

4 Las dos figuras que muestran la distribución espacial del territorio de Cañabravita fueron realizadas por miembros de la comunidad. 
Figura 3. Cabildo de Cañabravita

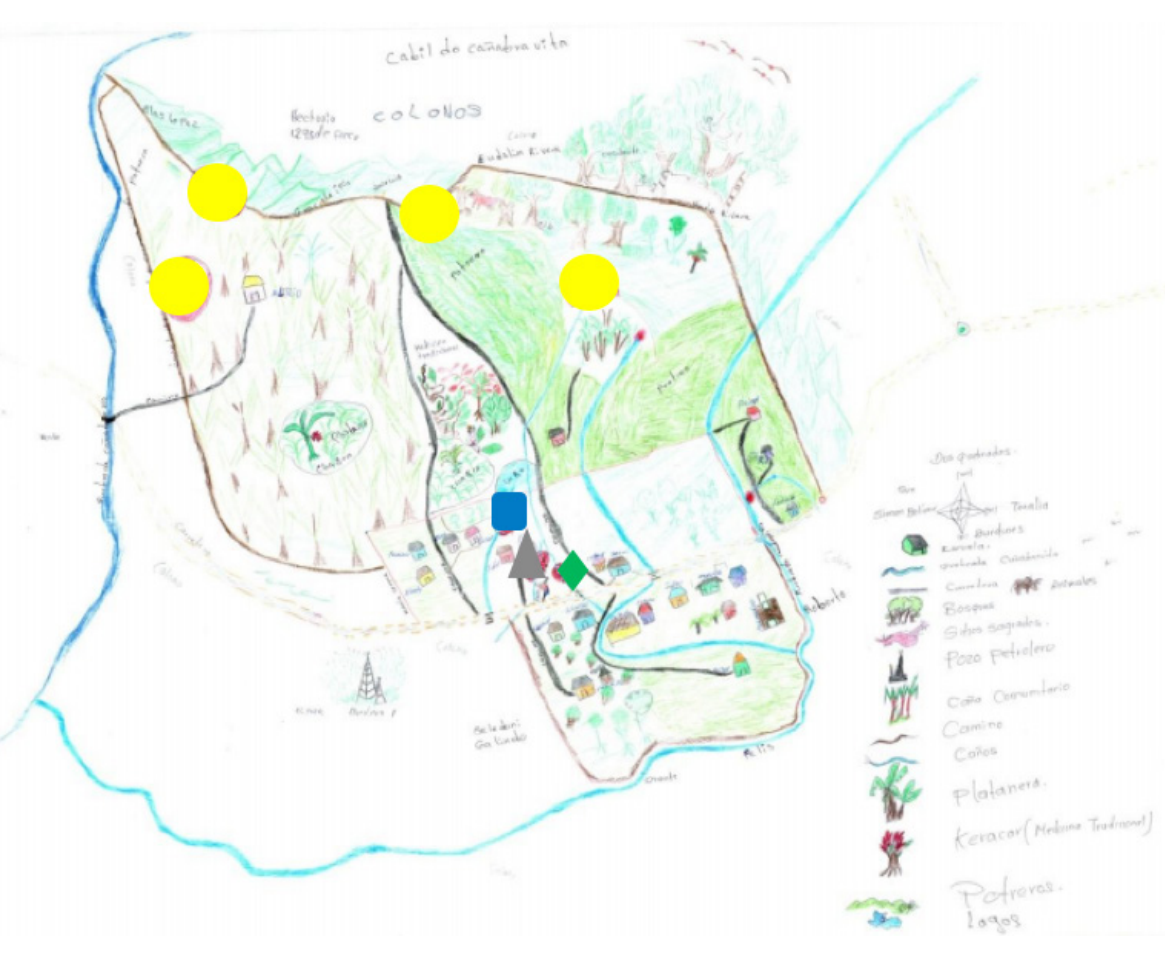

Fuente: Asociación Kipara (2011).

Como se puede apreciar en el mapa (Figura 3), humanos y no humanos comparten un mismo territorio, dicha cohabitación no es extraordinaria, dado que para los embera no es extraño desplazarse por la selva y sentir el olor de los jaïs, verlos o sentir su presencia, al punto que como lo ha señalado Losonczy (1997), la gente pregunte a alguien al verlo si es hombre o jaï. Es por ello que la expresión acuñada por Perrin (1995) monde-autre (mundo-otro) para referirse al espacio ocupado por los seres no humanos, no es la más precisa, pues humanos y no humanos conviven e interactúan en un mismo territorio. Pero, para que distintos seres puedan mantener una coexistencia en un mismo espacio, se requiere de un sistema del control de relaciones entre seres (individuos). 


\section{Relaciones entre humanos/no humanos y el control territorial}

Para dar cuenta de las estrategias utilizadas para controlar el territorio y sus habitantes en el cabildo ${ }^{5}$ de Cañabravita, se utilizará el concepto de biopoder, el cual se define como el conjunto de mecanismos por medio de los cuales los individuos hacen parte de una estrategia política, se trata de saber por dónde pasan las cosas (bienes, ideas, etc,), cómo pasan, entre quiénes, el procedimiento y los efectos; es decir, cuál es el conjunto de mecanismos y procedimientos cuyo papel consiste en asegurar el poder (Foucault, 2008).

En la sociedad embera el poder real recae sobre el dueño de casa, quien ejerce como jefe de familia, bajo su tutela están la esposa, hijos solteros, hijas solteras o casadas y yernos (los embera practican la matrilocalidad); sin embargo, cada día es más frecuente que el cabildo y la organización indígena regional embera (Asociación Kipara) tengan una mayor influencia en la vida de las personas, dado que es él quien determina los trabajos colectivos, la distribución de la tierra e impone castigos a los infractores de normas, entre otras actividades. No obstante, en la cotidianidad el poder recae sobre el jefe de familia y la autoridad tradicional que es el jaibaná (aquel que tiene muchos $j a i$ ); este último ejerce un gran poder en la comunidad y en la unidad territorial, en este caso el cabildo de Cañabravita, puesto que él ejerce influencia sobre las acciones de los seres humanos y no humanos. En Cañabravita, al inicio del presente siglo, residían dos jaibanás que estaban entrelazados por relaciones de consanguinidad; para el 2011 eran tres jaibanás, uno de ellos hijo de un chamán rival de Cañabravita.

La poligamia está presente entre los embera; como se mencionó anteriormente, el jaibaná posee tanto una familia humana como una no humana (esposa, hijos, suegros, cuñados, etc.), pero todos ellos están integrados dentro de una única unidad familiar. El hecho de ser el jefe de familia le permite al jaibaná controlar las acciones de sus hijos humanos y no humanos, lo que le da la posibilidad de controlar la convivencia pacífica de hombres y jaïs al interior del territorio. De no existir un

5 Institución político-administrativa que se adopta en Espańa en el medioevo y se implanta en el territorio americano a partir del siglo XVI. 
jaibaná en el territorio, así como normas de filiación y alianzas a respetar, los jaï actuarían libremente agrediendo (enfermando) a los seres humanos que se aproximen a sus sitios de residencia (jaide).

La presencia de los jaï asegura el control territorial, tanto al interior como al exterior del grupo de parentela ${ }^{6}$. Al interior, porque nadie desafía lo que dice el jaibaná, en particular en lo asociado con el manejo del territorio y sus recursos; a través de los contactos con las wadras, el jaibaná conoce de primera mano que toda sobre explotación del medio puede implicar la venganza de la wadra, quien castigará a los hombres (en especial a niños y mujeres) con enfermedades por no respetar la propiedad de ella. Al exterior, dado que el jaibaná localiza las casas de los jaïs (jaïde) y de los otros seres no humanos en los límites del territorio (como se evidencia en las Figuras 1 y 2), o no muy lejos de las áreas donde se localizan las casas de los humanos, para que los dos estén relativamente próximos pero a una distancia prudente y los no humanos puedan proteger a los humanos en caso de posibles agresiones de individuos (humanos o no humanos) ajenos al territorio del cabildo. Ello es particularmente notorio en el cabildo de Cañabravita, en donde los seres no humanos viven a poca distancia de los humanos, protegiendo a los habitantes de agresiones chamánicas provenientes de otras comunidades embera (en particular procedentes de uno de los jaibanás que antiguamente vivía en el cabildo de Villa Rica); ejemplo de ello, es cuando el doniur intentó entrar a una de las casas a agredir a las personas que en ella vivían, acción originada por no permitir que el hijo de un jaibaná, de una comunidad vecina a Cañabravita, se casara con una joven de la comunidad. La agresión terminó sin víctimas porque un perro dio aviso cuando sintió al domiur aproximarse y por medio de una acción chamánica, los seres no humanos que estaban en la proximidad, protegieron a los residentes de Cañabravita.

Como ha seńalado Godelier (2009), el sistema de parentesco penetra en los sistemas políticos, religiosos y económicos, circulando a lo largo de relaciones que el sistema privilegia, apareciendo bajo formas que los habría travestido o lo transfieren en otro código. En este caso, el parentesco se mezcla con lo político y lo chamánico; el jaibaná controla los jaïs porque ellos son sus aliados (suegros, esposas o cuñados) o

6 Grupo acéfalo constituido por el conjunto de consanguíneos bilaterales que reconoce ego (Barry, 2008). 
por sus relaciones de filiación (son sus hijos o nietos), es decir porque él es el jefe de la casa. Por ello él actúa como líder político, ya que controla las actividades de humanos y no humanos permitiendo que puedan cohabitar en un mismo territorio. Es por ello, como en el caso antes referenciado, que los seres no humanos protegieron a las familias de Cañabravita, puesto que los dos grupos están entrelazados por relaciones de alianza y filiación, construidas en torno al jaibaná del cabildo.

El sentido de seguridad que tiene una persona al estar dentro del territorio familiar (bien sea su pertenencia por alianza o filiación), favorece que el individuo busque afianzarse en él. Para ello, se requiere que él cumpla con las conductas atendidas por la colectividad de humanos y no humanos que residen en el territorio; en el caso contrario el infractor de normas deberá dejar el territorio, no es extraño que los jaïs (generalmente, pero no de manera exclusiva, por mandato del jaibaná) enfermen o generen mala suerte a las personas que rompen las pautas de conducta socialmente aceptadas, por ejemplo afectando a personas consideradas como chismosas, agresivas o mezquinas (Rubiano, 2009). Como lo señaló Piaget (1980), la conducta adquirida (a diferencia de la instintiva) lo es por asimilación del elemento nuevo (estimulo o respuesta) a un esquema reflejo; de este modo el embera aprende a no infringir normas sociales para evitar agresiones de humanos o no humanos. Ello es igualmente válido para los no humanos, que saben que agredir a los humanos puede tener como respuesta que un jaibaná los castigue (aniquile). De esta manera, todo aprendizaje se trata de un fenómeno de comunicación, que implica un cambio, lo que a su vez se inscribe en un proceso; existen diferentes categorías de aprendizaje, el cero (0) que es la recepción de una información de manera tal que un hecho análogo producido ulteriormente transmite la misma información, el aprendizaje I que es un fenómeno de hábito, el estímulo es una señal elemental y el contexto del estímulo un metamensaje que clasifica el signo, siendo por ello un refuerzo. Los siguientes aprendizajes son cambios en los aprendizajes anteriores (Bateson, 1977), es decir, el aprendizaje es un sistema de corrección y de refuerzo; de este modo, se puede entender la razón por la cual la proximidad entre humanos y no humanos es importante, se aprende viendo las consecuencias de las violaciones de las normas de conducta, lo que hace que se interiorice el porqué se deben respetar las normas de convivencia y el porqué se debe vivir en comunidad. Es por ello que la residencia en un territorio implica 
que el individuo debe someterse a las normas de convivencia que son tácitamente establecidas y reconocidas por quienes conviven en él.

En este contexto, el jaibaná es el regulador del medio que asegura diferentes tipos de circulación. Es él quien controla, al imponer límites a las acciones de los diferentes ocupantes del territorio, no solo haciendo posible la convivencia entre los ocupantes, sino también, el uso económico del territorio. Dado que es él quien pide permiso a los dueños originales del territorio, de las plantas y de los animales para que los humanos puedan hacer uso de ellos. Se está ante lo que Foucault (2008) calificó como sistema de reglamento disciplinario, en el cual lo determinado es lo que está permitido hacer y en donde el dispositivo de seguridad solo funciona bien con la condición de que se ceda en la libertad. Los embera deben actuar tal y como la norma lo prescribe, tanto hacia el territorio como hacia sus ocupantes, independientemente que sean humanos o no; siendo el jaibaná quien determina quién se excede en sus acciones, rompe las normas, por ende, puede o debe ser castigado.

Se debe señalar, que en este escenario la disciplina es por lo general centrípeta, es decir, funciona aislando un espacio; ella concentra, encierra, centra, circunscribe un espacio dentro del cual su poder y los mecanismos de este actúan en pleno y sin límites, por medio de codificar de manera permanente lo permitido y lo prohibido, esto es, lo que se debe hacer (Foucault, 2008). El embera sabe bien que él debe respetar las normas que el jaibaná o la tradición imponen dentro del territorio; si bien es cierto que muchas de ellas coinciden con las presentes en otros territorios embera, ello no es mecánico, por lo que se debe refrescar constantemente la memoria de los cabildantes, esto se hace mediante diferentes mecanismos tales como: los relatos de vida (que frecuentemente involucran a personas de la comunidad que han quebrantado alguna norma y el encuentro con seres no humanos), las agresiones de seres no humanos (en las ceremonias chamánicas se manifiesta que la aflicción del paciente está por lo general relacionada con la violación de alguna norma de convivencia) y por los rumores que por lo general involucran la mala suerte de alguien que ha roto alguna de las normas existentes. En la gran mayoría de ocasiones, el retornar al equilibrio, es decir, a un estado de bienestar, pasa por el llamado y la acción de un jaibaná, quien en medio de su actuar pone de manifiesto que la aflicción está ligada al no respetar alguna norma al interior del territorio, involucrando a sus habitantes. De esta manera, 
la actividad del jaibaná y de los no humanos, que están en su entorno, generan en los habitantes del cabildo lo que Foucault (2008) denominó como normatización disciplinaria, la cual consiste en plantear un modelo óptimo construido en función de determinados resultados, haciendo que la gente, los gestos y los actos se ajusten a un modelo prescriptivo; que en este caso se relaciona con el uso de territorio y con la manera como debe un individuo relacionarse con los otros seres (humanos y no humanos), con los que comparte dicho territorio.

Como manifestó Foucault (2008), los mecanismos de poder se encuentran en los mecanismos de seguridad; como él lo plantea en el caso de Occidente, el problema en el siglo XIX deja de ser la seguridad del territorio y de quien lo domina, pasando a ser circulatorio (personas, objetos o ideas), de manera controlada, seleccionar lo bueno y malo que circula, poniendo de relieve que la acción de quien gobierna es necesaria y suficiente. Se presenta, ya no la idea de un poder que adopta la forma de una vigilancia de los individuos y sus actos por un gobernante, en este momento se incorpora la jurisdicción del gobierno y de quienes gobiernan. Claramente, en el caso de los embera-chamí, no existe una jurisdicción de gobierno, ni un gobernante; en dicha sociedad el control del territorio y de sus habitantes se logra mediante el hacer cumplir las normas socialmente aceptadas. En dicho espacio social y territorial, el liderazgo social, en particular desde el punto de vista tradicional, es ejercido por el jaibaná, dicho liderazgo/poder, recae en quien por medio de la vigilancia del entorno social hace posible la convivencia y el uso del medio circundante; lo cual es posible mediante el control de las acciones de los seres no humanos, dado que ellas ejercen una influencia directa sobre el actuar de los humanos. Mediante el control de los no humanos, el jaibaná controla las acciones de los humanos, que hacen parte del grupo al cual él pertenece y al menos parcialmente, busca hacerlo con los otros grupos que viven en proximidad a ellos, esto mediante el temor que ejercen las actividades de los no humanos en la región. De esta manera, el jaibaná, mediante la vigilancia del actuar de los individuos, controla el territorio y su uso, al tiempo que ejerce un liderazgo sobre la colectividad. En un área de ocupación multiétnica, la presencia de un especialista en el control de seres no humanos es importante, los jaibanás de Cañabravita son conocidos en la zona y las comunidades afrodescendientes y campesinas prefieren evitar pescar en algunas partes de la quebrada Cañabravita 
porque en ella la gente se enferma (por la acción de los jaïs), pero por la misma razón los embera evitan algunas partes de la quebrada, lo que protege a los peces.

Los mecanismos de poder y de seguridad están íntimamente relacionados, encadenándose con el de población. En el caso de Occidente, hasta el siglo XVIII la población aparece como un elemento que condiciona los otros, dado que suministra brazos de trabajo y con ello la producción, la población es un principio de poder. A partir de este siglo la población es un dato dependiente de una serie de variables, lo que hace que la relación no pueda ser únicamente del orden de la obediencia o del rechazo, ella está sujeta a agentes y técnicas de transformación, ya no se obtiene la obediencia de los sujetos a voluntad del soberano, pero se influye sobre cosas que actúan sobre ella (Foucault, 2008). En el caso embera, dos tipos de población cohabitan en el territorio, los embera propiamente hablando y los no humanos, en particular los jaïs, cada uno de ellos sujeto a normas propias; por un lado los no humanos que son el "brazo de trabajo" de los jaibanás y por otro los humanos que son agentes sociales no necesariamente obedientes a lo que dice este último. Los jaïs realizan las actividades que son mandadas por el jaibaná, es decir, producen lo que se les ordena (control social y del territorio); los hombres, por el contrario, no necesariamente hacen lo que el jaibaná dice, sin embargo, por el solo hecho de que él sea un chamán, logra influir en su comportamiento, a partir de la amenaza tácita de castigar el no cumplimiento de las normas sociales (por ejemplo "acumular riqueza", hecho que se correlaciona con una sobreexplotación del medio social o ambiental) o por el contrario de dar el acceso a aquello que los individuos requieren o consideran socialmente necesario (como es la salud o el acceso a áreas de caza). Es decir, que hay pluralidad de formas de gobernar a los individuos que cohabitan un territorio, así como una inmanencia en las prácticas de "gobierno" del jaibaná. El jaibaná "gobierna", es decir, direcciona, sobre un territorio y los que en él residen, sin embargo, él no impone normas, esto lo hace la sociedad, él dispone de los mecanismos que hacen que esas normas se cumplan, pero él toma esas iniciativas a partir de la solicitud de los miembros de la colectividad o cuando lo considera pertinente, a partir de su propia iniciativa, pero siempre como uno más de la colectividad. Pero, si el jaibaná es quien direcciona, cabe preguntarse, ¿cuál es el uso que se da al territorio? Y, ¿̇uál es el papel del jaibaná en ello? 


\section{El uso del territorio}

Godelier (1984) define el territorio como una porción de la naturaleza y del espacio sobre la cual una sociedad reivindica a todos o a una parte de sus miembros, derechos estables de acceso, de control y de uso de los recursos que en ella se encuentran, es decir, es el lugar donde sus miembros encuentran de manera permanente las condiciones y los medios materiales de su existencia. Como se evidencia entre los embera, esta noción es solo parcialmente cierta; por un lado, la sociedad embera comparte un territorio con miembros de comunidades humanas ajenas a la suya; campesinos, afrocolombianos y embera cazan, pescan y recolectan productos en áreas compartidas (que bien pueden ser baldíos o espacios no trabajados de predios que tienen un poseedor), pero también trabajan en espacios que son propiedad de un particular, ofreciendo su mano de obra como jornaleros o medieros ${ }^{7}$. En estos espacios, ellos tienen el acceso, el uso, pero no el control; sin embargo, en muchas ocasiones estas áreas (en especial las de caza, pesca y recolección) son reivindicadas como propias por los embera, es por ello que la definición de territorio debe condicionarse al acceso y al uso, pero no al control; ello es aún más vigente al introducir a los no humanos en el sistema de relacionamiento social al interior de las colectividades que comparten un territorio.

Por otro lado, el territorio es compartido con seres no humanos, con los que se pueden tejer lazos de parentesco, ellos poseen el acceso, el uso y el control del territorio, pues son sus poseedores originales, y con ellos se debe negociar para hacer uso de él. Para poder desplazarse por el territorio, es menester "encerrar" los jaïs o en general cualquier tipo de ser no humano que habite el territorio, para ello el jaibaná mediante su actividad ritual entra en contacto con los seres que ocupan el territorio y establece con ellos relaciones de alianza o amistad. Mediante la generación de lazos de parentesco, se adquiere el acceso y el derecho de uso del territorio, sin embargo, el control está condicionado a la interacción entre los habitantes, es decir, que para poder vivir y hacer uso de los recursos que se encuentran al interior de un territorio, el jaibaná debe acordar con los habitantes originales, que los hombres puedan

7 La mediería es un contrato agrícola asociativo en donde el propietario de la tierra aporta el derecho de uso del suelo y el agricultor (mediero) su mano de obra. Por lo general se dividen en parte iguales las utilidades de la producción agrícola. 
realizar actividades en el área, por ejemplo, se debe llegar a un acuerdo para que la gente pueda pescar o pasar en proximidades a los puntos del río donde vive el documa o el doniur; del mismo modo, se requiere pedir a wadra el acceso a los animales de caza (que se traduce en la prohibición de la parte de ella a dejar heridos los animales o matar más de lo debido); en el caso del cabildo de Cańabravita, pero también del cabildo embera-chamí de Villarica, los jaibanás negociaron con la wadra de un área de selva conocida como la ciudad de los monos para poder ir a cazar. Sin embargo, dicho permiso puede ser retirado en ciertas épocas del año, en los cuales si la gente va no atrapará ninguna presa o caerá enferma. Ello muestra que los humanos deben negociar en la cotidianidad con los no humanos los derechos de uso y acceso al territorio; es decir, que los humanos y no humanos (así como grupos humanos entre sí) pueden compartir un territorio negociando el acceso, el control y el uso, lo que no hace que dicho territorio sea menos suyo.

Si el acceso, control y uso del territorio debe ser negociado entre las colectividades que lo comparten, el derecho a ocupar y hacer uso de un territorio se asocia a su propiedad; y ella se da cuando los miembros se sirven de sus reglas, para organizar sus conductas concretas de apropiación (Godelier, 1984), en otras palabras, de su uso. Desde esta perspectiva, el territorio es de una colectividad porque ella ha negociado con otras su acceso, su uso y su control, derechos que en el caso embera son compartidos con otras comunidades en particular no humanas. La persona en quien recae dicha negociación es el jaibaná y por lo tanto es él quien impone al mundo de los hombres las normas de acceso y uso del territorio.

Es por ello, que se puede decir que el derecho a hacer uso de un territorio y, como lo manifiesta Godelier (1984), de tener la propiedad de la naturaleza, se presenta como un aspecto de las relaciones de parentesco. En el caso de las sociedades de tierras bajas, como la embera, esto se basa en las construcciones sociales que elaboran los jaibanás emparentando desde relaciones de alianza y de filiación a humanos y no humanos que comparten un territorio.

La actividad del jaibaná para garantizar a la colectividad el acceso a un territorio y el uso del mismo, requiere del manejo del arte de gobernar, el cual consiste en 
manipular, mantener, distribuir y restablecer relaciones de fuerza, dentro de un espacio de competencia que implica un desarrollo competitivo (Foucault, 2008). Mediante los contactos, intercambios y con la entrega de dones (cargados de la esencia de los seres humanos, en especial licores y comida que se da durante las ceremonias) que el jaibaná realiza con los seres no humanos, el primero manipula a estos últimos para que ellos permitan el establecimiento y el uso del territorio por parte de los hombres, lo que se traduce en la posibilidad de abrir cultivos y espacios para hacer casas, o la posibilidad de cazar, pescar o recolectar en la selva. Simultáneamente, se restablecen y modifican relaciones de fuerza, a partir de los dones, pero también de dominar a los no humanos en combates chamánicos. De este modo el jaibaná adquiere el control de las comunidades no humanas que ocupan el territorio; al dominar dichos seres (que son reconocidos por los embera como potencialmente peligrosos) él adquiere la facultad de influenciar el comportamiento de los humanos, quienes saben que, el mal manejo o la sobreexplotación del medio social o natural, será penalizado por el jaibaná o por los jäis. El control del territorio y de los seres que originalmente lo ocupaban le permite al jaibaná manipular, mantener, distribuir y restablecer relaciones de fuerza, en otras palabras, controlar las actividades de los hombres.

La realidad etnográfica embera permite acompañar lo planteado por Godelier (1984), quien pone de relieve que lo que reivindica una sociedad apropiándose de un territorio es el acceso, control y uso tanto de realidades visibles como de potencias invisibles que lo componen y parecen compartir el dominio de las condiciones de la reproducción de la vida. Cuando los embera llegan por primera vez a un territorio, el jaibaná lo debe "domesticar" para hacer posible la instalación de los humanos y el uso del mismo por parte de ellos, es dicha "domesticación", que mejor se debe entender como dominación, lo que nos da una mejor aproximación al pensamiento de las sociedades de tierras bajas de América. El acceso al territorio pasa por someter y dominar a los seres que originalmente lo ocupan, que son quienes hasta ese momento tenían el control de los elementos que hacen parte del territorio.

En este momento, es muy importante aclarar que para los embera todo lo que existe en el "mundo" material existe simultáneamente en el "mundo" inmaterial (espiritual como ellos mismos suelen decir), por lo tanto toda planta, animal, mineral, río u 
objeto que el hombre puede ver, palpar u oír, posee una especie de doble en dicho "mundo" (y para complejizar la situación los dos "mundos" pueden ocupar u ocupan un mismo espacio), al cual el jaibaná somete y con ello adquiere la capacidad de controlar las condiciones de la reproducción de la vida.

De este modo, para los embera el control del territorio y su uso son percibidos y se enmarcan dentro de construcciones sociales, las cuales se establecen entre humanos y no humanos, después de todo, las montañas, las plantas, los animales, los ríos, son seres sociales.

\section{COMENTARIOS FINALES}

La manera como los embera del cabildo de Cañabravita, reivindican, tienen acceso, control y uso del territorio, pone de manifiesto que él hace parte del conjunto social, en donde diferentes colectividades cohabitan. Entre ellas se tejen redes sociales articuladas en torno al jaibaná y en donde la máxima expresión de su capacidad es el control del territorio, y por lógica propia, de sus habitantes.

Como lo ha señalado Descola (1996), al dotar a la naturaleza de propiedades sociales los hombres socializan en lo imaginario la relación ideal que establecen con ella, tomando como modelo las relaciones sociales en las cuales ellos están inmersos. El territorio es un ser social, cada uno de los elementos que lo componen es un ser, no humano, y con ellos se deben entablar relaciones para acceder al territorio, las cuales tienen como referente la inscripción en el sistema de parentesco de los embera, y simultáneamente en la redes sociales que el sistema social contempla, con los deberes y derechos que demanda estar en él.

El territorio es un espacio social de seres antropomorfizados, el cual puede ser definido retomando a Condominas (1980) como la unión de sistemas de relaciones características de un grupo determinado; es decir, en una entidad que incluye otros sistemas de relaciones, dando cuenta de relaciones mantenidas con grupos vecinos como con aquellos que absorbe, lo que se traduce notablemente por la relación que 
se tiene con seres sobrenaturales. Lo que es inseparable del medioambiente y ordena su sistema simbólico y de valores, por lo cual, no se puede reducir el espacio social al geográfico.

Para comprender la manera como una sociedad amerindia de tierras bajas piensa el territorio e interactúa con él, es menester identificar, cómo sus componentes son percibidos como seres, y cómo ellos se encuentran inmersos en los sistemas sociales que caracterizan a la comunidad o comunidades que interactúan; al tiempo que se debe ver cómo ellos hacen parte de los sistemas políticos, económicos religiosos y de parentesco que dan forma al sistema social del grupo.

En este marco, es interesante aproximarse a la noción de gubernamentalidad elaborada por Foucault (2008), quien la define como un conjunto constituido por las instituciones, los procedimientos, análisis y tácticas que permiten ejercer la forma específica de poder que tiene por blanco la población. En la sociedad embera tradicional, esta noción permite ver cómo el chamanismo articula a la sociedad embera con la no humana, con la cual comparte un espacio geográfico/social de existencia, poniendo de relieve la manera como se construyen relaciones sociales y políticas, entre dos grupos sociales entrelazados por el sistemas de parentesco o redes de intercambio que permiten manipular a humanos y no humanos con el fin de hacer uso del medio de una manera controlada por el jaibaná. En este estado toda acción chamánica (religiosa), es a la vez política y social, enmarcada en un espacio que sobrepasa los límites del resguardo para dar forma al territorio embera, que es el espacio de articulación social en el cual está inmersa la comunidad, en este caso del cabildo de Cañabravita y del cual hacen parte los embera, las comunidades campesinas y afrodescendientes vecinas, como de jä̈s o de otros seres no humanos con los cuales se comparten relaciones que se inscriben en espacios que dan forma al territorio embera-chamí.

Para terminar, es importante señalar como lo ha hecho Descola (1996), que cuando una sociedad concibe el uso de la naturaleza como homólogo de un tipo de relación entre hombres, toda modificación de este uso debe pasar por una reorganización de la representación de la naturaleza como del sistema social que sirve para pensar 
metafóricamente su explotación. Teniendo como referente que el presente documento se basa en un trabajo de campo realizado en los primeros ańos del presente siglo, a futuro cabe preguntarse, ¿cómo el reciente aumento de poder del cabildo frente a la autoridad tradicional que es el jaibaná, o la llegada de proyectos con recursos que han traído consigo la ampliación de los territorios del cabildo y proyectos productivos, están modificado las relaciones de los embera con los no humanos? Y, ¿si ello está generado cambios en la manera de concebir el territorio? Esto muestra que la concepción que se tiene del territorio es dinámica y está influenciada por múltiples factores, de ahí la necesidad de mantener estudios constantes sobre él.

\section{REFERENCIAS}

Asociación Kipara. (2011). Plan de salvaguarda del pueblo embera del Putumayo. Manuscrito sin publicar.

Bateson, G. (1977). Vers Une Écologie De L'esprit. París, Francia: Éditions du Seuil.

Barry, L. (2008). La Parenté. París, Francia: Éditions Galimar.

Condominas, G. (1980). L'Espace Social Á propos De L'Asie Du Sud-Est. París, Francia: Flammarion.

Descola, P. (1996). La selva culta, simbolismo y praxis en la ecología de los achuar. Quito, Ecuador: Abya-Yala.

Foucault, M. (2008). Seguridad, territorio, población. Curso en el collège de France (19771978). México D. F., México: Fondo de Cultura Económica.

Godelier, M. (1984). L’idéel et le matériel. Pensée, économies, sociétés, París, Francia: Fayard.

Godelier, M. (2009). Corps, parenté, pouvoir(s) chez les baruya de Nouvelle-Guinée. En M. Godelier y M. Panoff, Le corps humain conçu, supplicié, possédé, cannibalisé (pp. 29-64). París, Francia: CNRS Editions. 
Losonczy, A-M. (1997). Les saints et la forêt, París, Francia: L'Harmattan.

Perrin, M. (1995). Le chamanisme. París, Francia: PUF.

Piaget, J. (1980). Biología y conocimiento. México D. F., México: Siglo Veintiuno Editores.

Rubiano, J. C. (2009). Juegos sociales: agresión y chamanismo entre los embera-chamí del Putumayo. Boletín de Antropología, 23(40), 32-54.

Rubiano, J. C. (2010). L'Homme-Forêt: Action Sociale et Action Rituelle dans le Chamanisme Embera-Chami (tesis doctoral). École Pratique des Hautes Études, París, Francia. 